\title{
Radiological Assessment of Target Debris in the National Ignition Facility
}

\author{
Hesham Khater \\ Lawrence Livermore National Laboratory \\ 7000 East Ave, L-462, Livermore, CA 94550, USA \\ khater1@1lnl.gov
}

\author{
Sandra Brereton \\ Lawrence Livermore National Laboratory \\ 7000 East Ave, L-580, Livermore, CA 94550, USA \\ brereton1@1lnl.gov
}

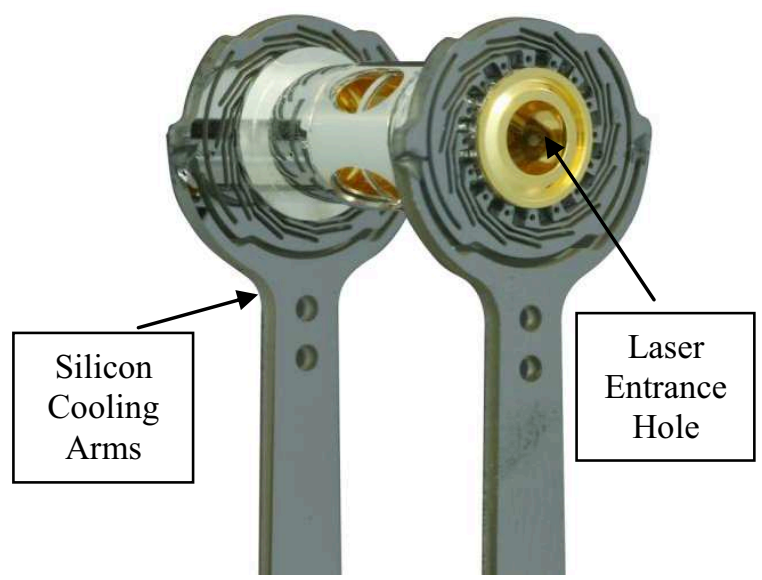

Figure 1. Prototype ignition target.

In this paper, an assessment of the radiological hazards associated with the NIF target debris is presented. A specific emphasis is placed on evaluating the external radiation hazard present during maintenance activities as a result of the activated debris.

\section{NIC IGNition PoInt Design TARget}

A variety of target materials are considered for use during the National Ignition Campaign (NIC). This paper focuses on analyzing the few capsule and hohlraum materials that are part of the current NIF shot plan. Targets fabricated by General Atomics consist of a fuel capsule that is about $150 \mu \mathrm{m}$-thick and with an inner diameter of $1040 \mu \mathrm{m}$. Two types of capsules are considered. The first type is made of a high-quality beryllium alloy that contains about 0.35 at $\%$ copper. The second option is to use a hydrocarbon $(\mathrm{CH})$ that is doped with germanium also at about $0.35 \mathrm{at} \%$. The purpose of adding dopant to the capsule material is to fine-tune its $x$-ray absorption and to smooth the solid layer of D-T fuel on its inner surface. Surrounding the capsule is a hohlraum in the shape of a cylinder with an inner wall measuring about $5 \mathrm{~mm}$ diameter and $9 \mathrm{~mm}$ high. Fig. 2 shows the current NIC ignition point design target. The three types of ignition hohlraums considered are made of gold ( $\mathrm{Au}$ ), depleted uranium (DU), or a mixture of depleted uranium and gold $(75 \%$ DU and $25 \% \mathrm{Au})$. The inner surface of this $10 \mu \mathrm{m}$-thick hohlraum is covered with a $0.2 \mu \mathrm{m}$-thick layer of gold or a mixture of gold and boron ( $80 \% \mathrm{Au}$ and $20 \% \mathrm{~B}$ ). The hohlraum is surrounded with a 42 $\mu \mathrm{m}$-thick layer of gold to prevent oxidation and provide 
structural support. The hohlraum and the gold support are enclosed in a $150 \mu \mathrm{m}$-thick aluminum can made of Al-5052 alloy. Finally two silicon cooling arms surround the aluminum can. An assessment of the impact of activating these materials on radiation dose has been considered. Except for noble gases and iodine generated as a result of DU fission, all other radioactive isotopes were assumed to stay inside the TC (deposited on first wall panels).

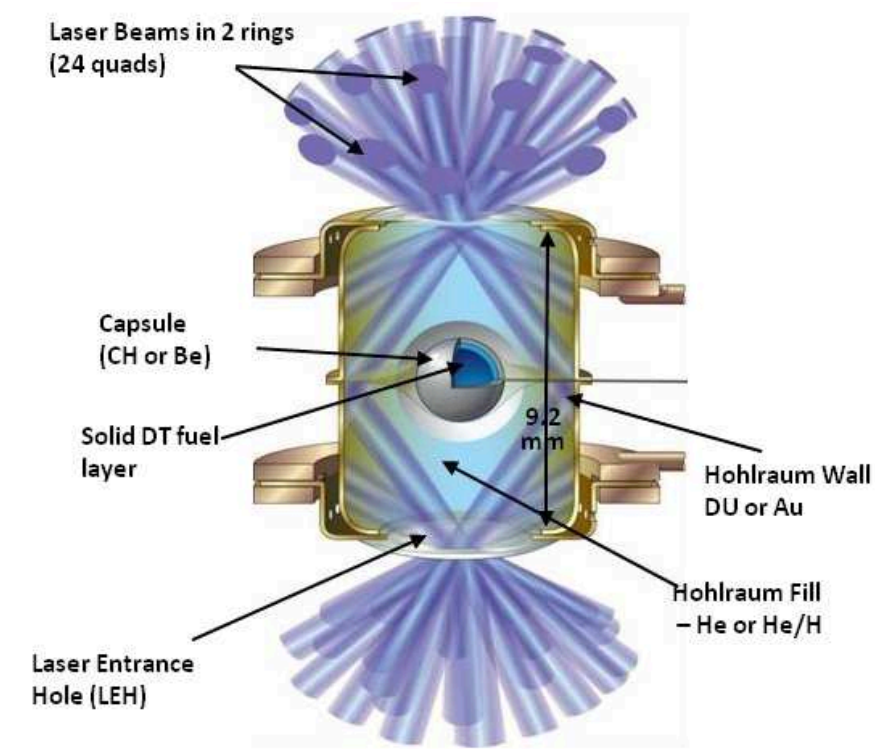

Figure 2. NIC ignition point design target.

\section{CALCULATIONAL PROCESS}

A three-Dimensional model of the hohlraum has been developed using the MCNP5 radiation transport code [1]. The hohlraum is placed in a detailed model of the Target Chamber. The TC is a sphere with an inner radius of $5 \mathrm{~m}$ and a $10-\mathrm{cm}-$ thick wall made of the low activation aluminum alloy (Al 5083). The chamber wall is covered on the inside by steel panels made of the low activation stainless-steel 409 alloy. In addition, the TC is surrounded on the outside by $40-\mathrm{cm}$ of borated concrete, which acts as a neutron shield. The neutron transport calculations utilized neutron cross section data from the FENDL-2.1 cross section database [2]. Neutron fluxes were calculated for all materials considered for the target capsule and hohlraum as well as the first wall panels, target chamber and the gunite shield. These fluxes were then used to calculate the level of radioactivity induced in each material following one shot as well as at the end of one year of operation. One year of operation is modeled as sixty $20 \mathrm{MJ}$ shots with 6.18 days in between shots. The 175-group FENDL/A-2.0 activation cross-section library [3] along with the FENDL/D-2.0 decay data library were used by the activation code ALARA [4] to calculate the radioactive inventory and decay gamma source for all materials except for DU. The $14 \mathrm{MeV}$ neutrons will induce fission reactions in the uranium atoms, resulting in the generation of a large number of fission products. Activation of DU was also performed by ALARA by using the CINDER'90 63-group neutron data library [5]. The calculated decay gamma sources were finally transported by MCNP5 to calculate the effective dose at selected locations inside and outside the TC and as a function of time following shots. The effective dose values were calculated by using ICRP-74 Anterior-Posterior (AP) neutron fluence-to-dose conversion coefficients [6].

\section{RESULTS}

Radiation dose rates are the highest inside the Target Chamber. Following a shot, the activated target materials are expected to be uniformly deposited on the surface of the first wall steel panels. As such, one would expect that any maintenance activities inside the TC would include exposure to gamma decay from the activated target material as well as decay from the activated first wall steel panels, aluminum chamber and gunite shield. A second potential for exposure occurs outside the TC and is caused by fission gases resulting from the decay of the DU fission products. Following a shot it is assumed that all activated target materials and their decay daughters stay in the chamber and do not escape. This is not true for noble gases and iodine. Noble gases will most probably escape to the cryo-pumps outside the chamber. The same is true for iodine which may escape in the form of hydrogen iodide or methyl iodide.

\section{A. Maintenace inside the Target Chamber}

Dose rates were calculated for potential maintenance activities under the assumption that the maintenances tasks would be performed at a distance of 1' from the first wall panels (FW). Fig. 3 shows the dose rates expected due to activated capsules materials considered in this analysis.

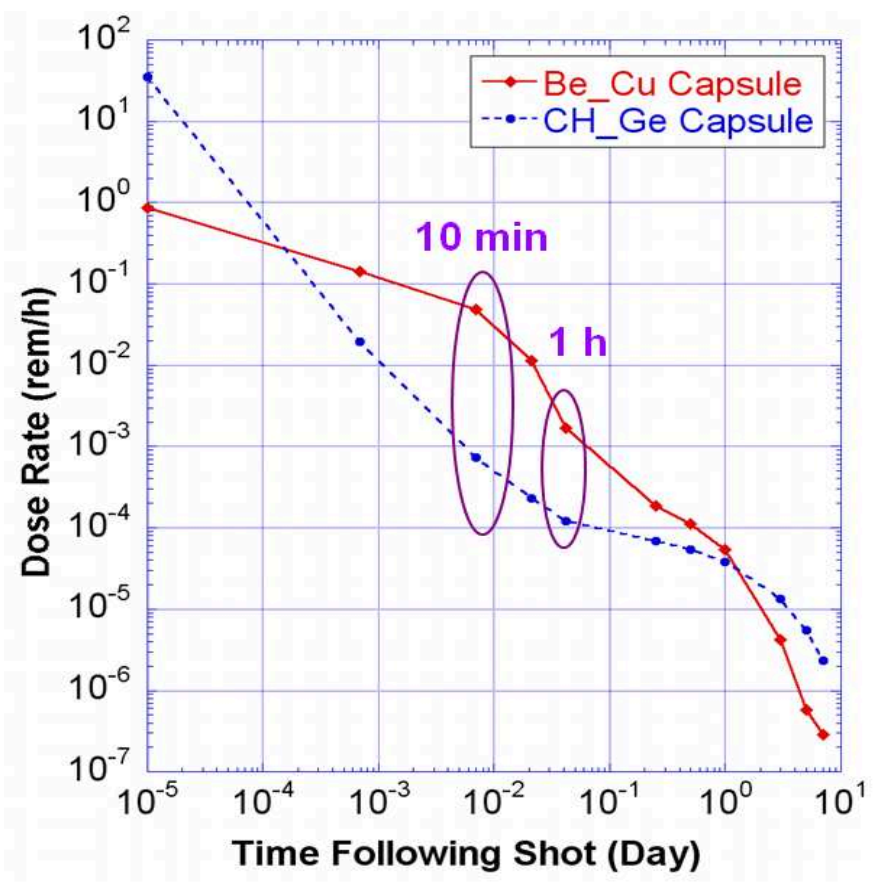

Figure 3. Dose rates due to different capsules at 1'from FW.

The hazard inside the TC due to activated capsules is very small with $\mathrm{Be}$ capsules producing a higher dose than $\mathrm{CH}$ during the first day. The dose rate due to activation of a $\mathrm{Be}$ capsule drops to $1 \mathrm{mrem} / \mathrm{h}$ after one hour. The Be capsule dose is dominated by contributions from $\mathrm{Cu}$ isotopes, ${ }^{62} \mathrm{Cu}$ and ${ }^{66} \mathrm{Cu}$. The $\mathrm{CH}$ capsule dose rate drops to a similar level within 10 minutes. In this case, the dose is dominated by ${ }^{74} \mathrm{Ga}$ during the first hour, and ${ }^{72} \mathrm{Ga}$ and ${ }^{69} \mathrm{Ge}$ during the first day. In short, 
capsule activation is dominated by activation of added material/dopant.

A comparison between the potential hohlraum materials is shown in Fig. 4. The dose rate due to activation of the $10 \mu \mathrm{m}$ DU hohlraum wall drops to $1 \mathrm{mrem} / \mathrm{h}$ after one week. The DU dose is dominated by the fission products. Isotopes like ${ }^{88} \mathrm{Ga}$, ${ }^{92} \mathrm{Sr}$ and ${ }^{142} \mathrm{La}$ dominate during the first hour. At one day the DU dose is dominated by isotopes like ${ }^{132} \mathrm{I},{ }^{135} \mathrm{I}$ and ${ }^{91} \mathrm{Sr}$. The $\mathrm{Au}$ dose is caused by the decay of ${ }^{197 \mathrm{~m}} \mathrm{Au}$ during the first minute with ${ }^{196} \mathrm{Au}$ responsible for dose beyond the first minute.

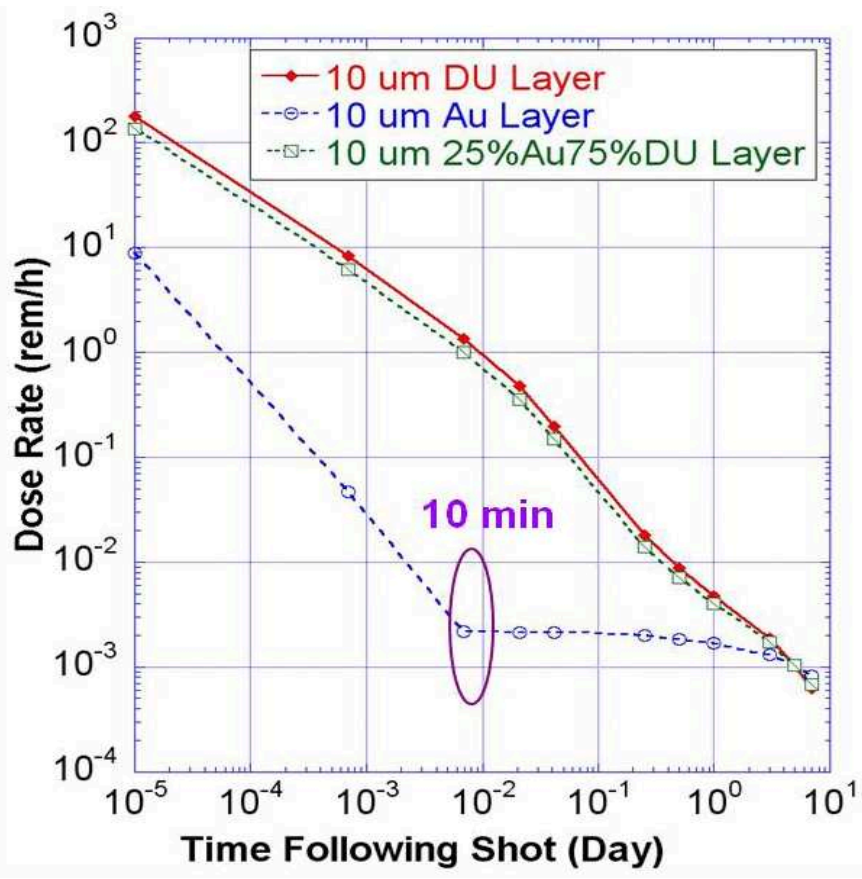

Figure 4. Dose rates due to different hohlraum materials at 1'from FW.

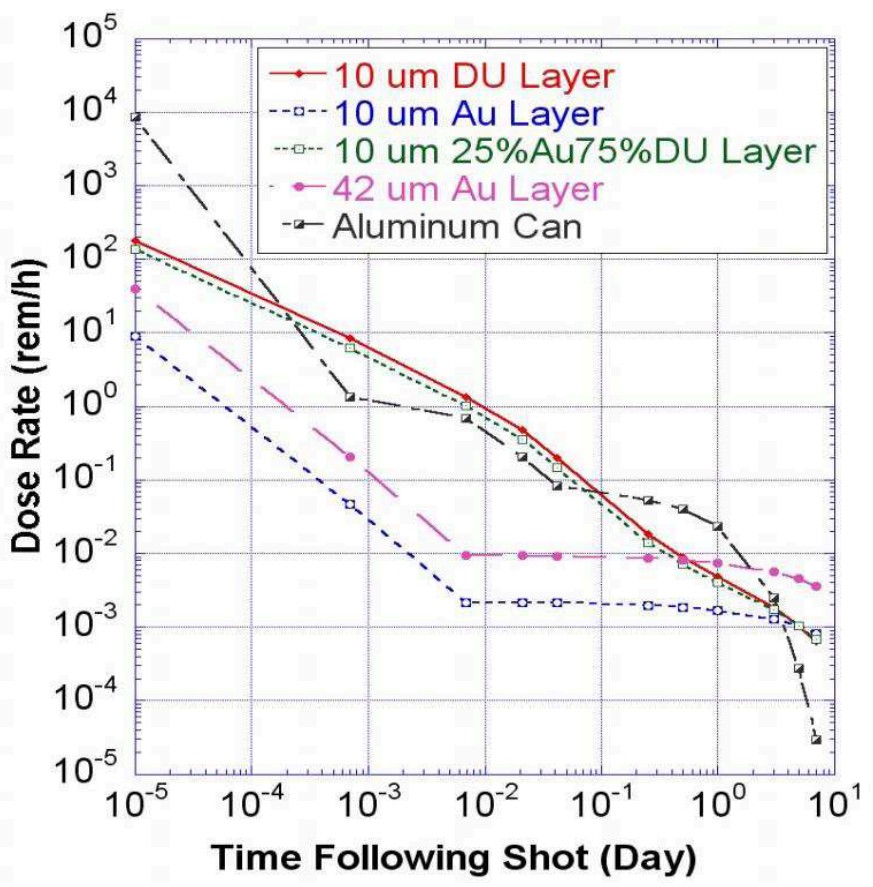

Figure 5. Dose rate comparison for target materials at 1' from FW.
A DU hohlraum continues to generate higher dose rates than the gold hohlraum for up to a week following the shot. Due to the long dwell time between the shots, the dose rates are almost entirely dominated by the last target shot. Target materials from previous shots will decay out between the shots while being exposed to about 6 orders of magnitude lower flux after being deposited on the first wall panels (i.e., very little amount of additional activation is added to the previously activated target materials after being deposited on the first wall).

As mentioned before, the hohlraum is surrounded by a 42 $\mu \mathrm{m}$-thick layer of gold and both are enclosed in a $150 \mu \mathrm{m}$-thick aluminum can made of Al-5052 alloy with two silicon cooling arms surrounding the aluminum can. A comparison between these components shows that both the aluminum can and the DU hohlraum generate an equivalent level of dose rate during the first few hours. As shown in Fig. 5, the very short-lived ${ }^{24 \mathrm{~m}} \mathrm{Na}$ generates a high dose rate from the aluminum during the first few seconds. A higher dose contribution from the can is also shown during the first 3 days, a period of time during which ${ }^{24} \mathrm{Na}$ is the dominate isotope. The dose rate due to the 42 $\mu \mathrm{m}$ layer of gold exceeds the DU dose within 12 hours.

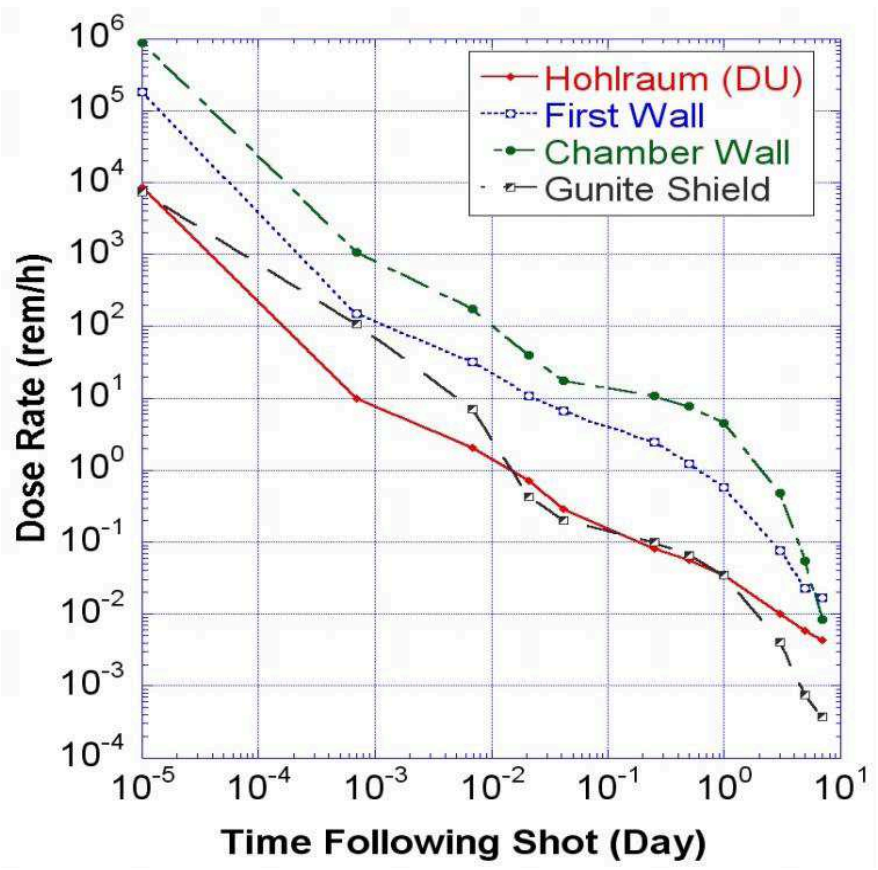

Figure 6. Dose rates at 1' from FW.

Fig. 6 shows a comparison between dose from activated target material (everything inside an aluminum can with a DU hohlraum) to doses from first wall, chamber wall and the gunite shield. ${ }^{24} \mathrm{Na}$ generated in the activated $\mathrm{Al}$ chamber dominates the dose inside the TC during the first week. ${ }^{56} \mathrm{Mn}$ and ${ }^{54} \mathrm{Mn}$ generated in activated first wall stainless-steel 409 are the second and third largest contributors. The contribution from activated target materials is orders of magnitude lower than the Al chamber.

\section{B. Doses due to Fission Products}

Fission products are generated from the DU hohlraums. Following a shot, it is fair to assume that most of the fission 
products will stay inside the Target Chamber and hence limit the radiological hazard to inside the TC. Nevertheless, even though noble gas precursors will stay inside the chamber, noble gases like krypton and xenon as well iodine will most probably leave the chamber and end-up accumulating on the cryopumps. This could pose a potential source of dose during maintenance activities in the vicinity of the cryo-pumps. In addition, any regeneration of the cryo-pumps will send the gases to areas outside the Target Bay, such as to the radchem diagnostic. The radchem diagnostic measure the fusion yield by evaluating the level of activation of added tracers like, ${ }^{134} \mathrm{Xe}$, ${ }^{85} \mathrm{Kr},{ }^{127} \mathrm{I}$ and ${ }^{79} \mathrm{Br}$, to the D-T fuel.

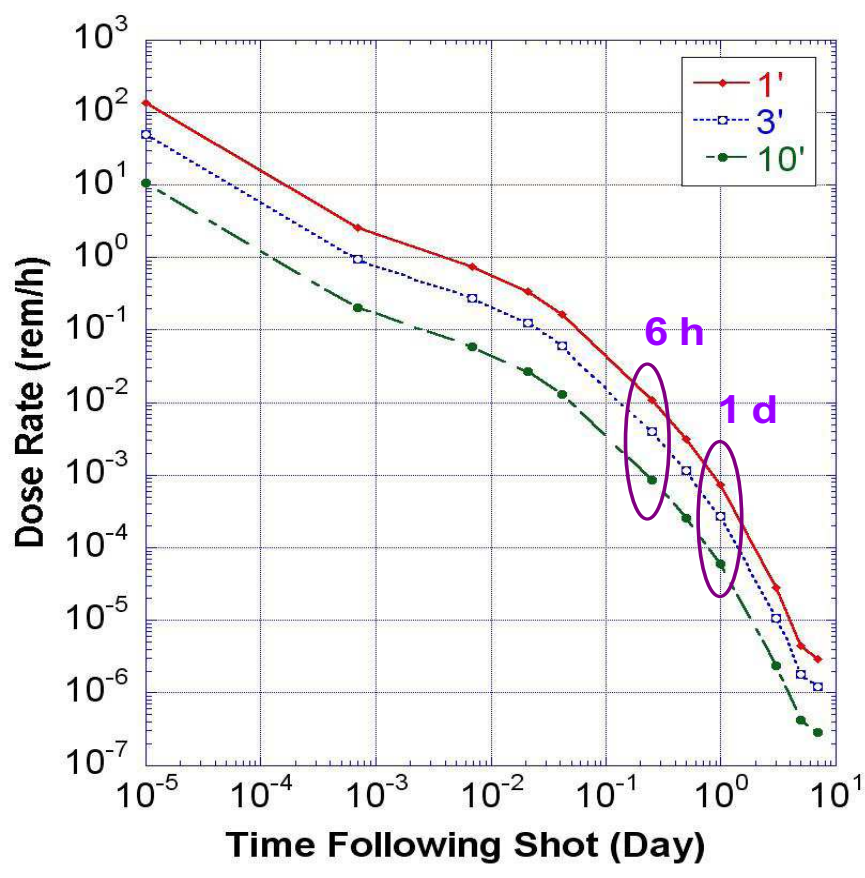

Figure 7. Dose rates due to noble gases outside cryo-pumps.

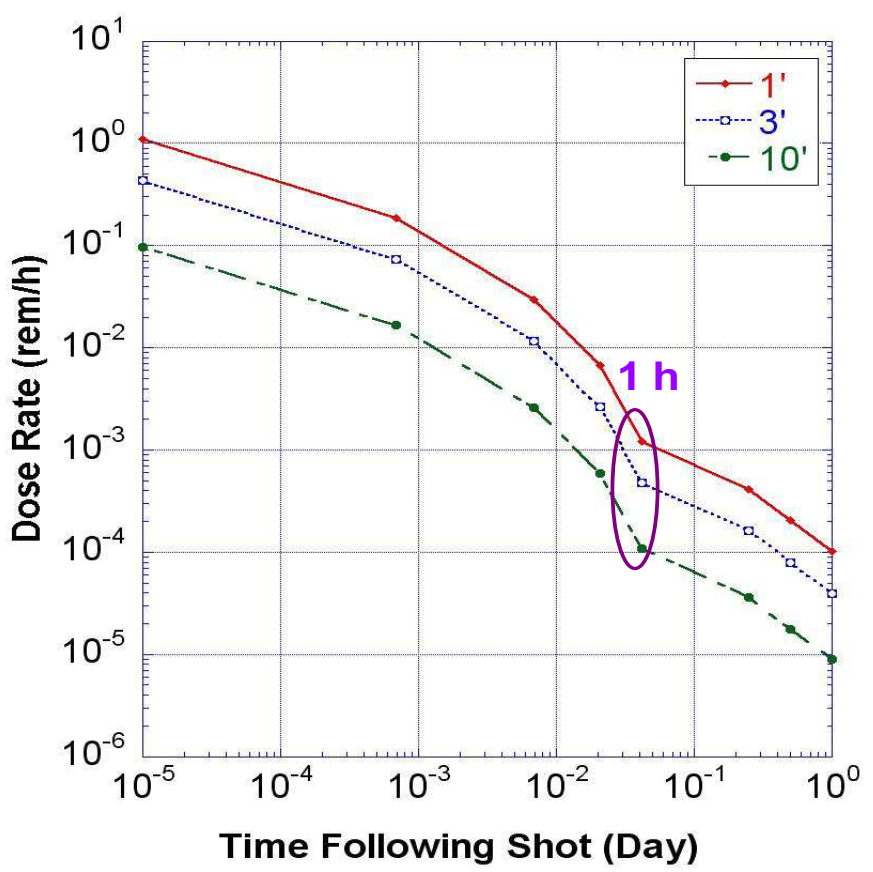

Figure 8. Dose rates due to iodine outside activated carbon filters.
Fig. 7 shows the expected dose rates outside the cryo-pump at the radchem gas collection skid as a function of distance following a $20 \mathrm{MJ}$ shot. Dose rates in the figure assume that the entire inventory of activated noble gases is transported outside the TC. ${ }^{87} \mathrm{Kr},{ }^{88} \mathrm{Kr}$ and ${ }^{138} \mathrm{Xe}$ are responsible for most of the dose during the first few hours following the shot. Within a day, the dose rate at a distance of 1' drops below 1 $\mathrm{mrem} / \mathrm{h}$. Hence, a wait period of about one day is recommended before transporting noble gases outside the Target Bay for radchem analysis. Transporting a small fraction of the gas inventory will allow for faster access to the skid.

Finally, effluent from the TC cryo-pumps sent to the Tritium Processing System (TPS) will include radioactive iodine. Smaller molecules containing iodine (such as HI) will be held up in the dryer beds in TPS. Larger molecules (such as methyl iodide) will pass through and be captured in the activated carbon filter. As shown in Fig. 8, regenerating the cryo-pumps after waiting for one hour will reduce dose rates caused by iodine capture to $<1 \mathrm{mrem} / \mathrm{h}$ at 1 ' distance from the filters.

\section{SUMMARY}

Detailed activation analysis and dose rate calculations are performed for the different target materials under consideration for use at the National Ignition Facility. The use of $\mathrm{Be}-\mathrm{Cu}$ or Ge-doped $\mathrm{CH}$ capsules results in small external dose rates. Gold and depleted-uranium are considered as potential hohlraum materials. The dose rate due to activation of a $10 \mu \mathrm{m}$ DU hohlraum wall drops to $1 \mathrm{mrem} / \mathrm{h}$ after one week. A DU hohlraum continues to generate higher dose rates than the gold hohlraum for up to a week following a $20 \mathrm{MJ}$ shot. During maintenance inside the $\mathrm{TC}$, the aluminum chamber dominates the dose during the first week. ${ }^{56} \mathrm{Mn}$ and ${ }^{54} \mathrm{Mn}$ generated in activated first wall stainless-steel 409 are the second and third largest contributors. Contribution from activated target materials is orders of magnitude lower than the Al chamber.

\section{ACKNOWLEDGMENT}

This work performed under the auspices of the U.S. Department of Energy by Lawrence Livermore National Laboratory under Contract DE-AC52-07NA27344.

\section{REFERENCES}

[1] X-5 Monte Carlo Team, “"MCNP - A General Monte Carlo N-Particle Transport Code, Version 5," Los Alamos National Laboratory, LA-UR03-1987, 2005.

[2] D. L. Aldama and A.Trkov, "FENDL-2.1: Evaluated Nuclear Data Library for Fusion Applications," International Atomic Energy Agency, INDC(NDS)-467, 2004.

[3] A. Pashchenko et al., "FENDL/A-2.0: Neutron Activation Cross-Section Data Library for Fusion Applications," Report INDC (NDS)-173, IAEA Nuclear Data Section, March 1997.

[4] P. WILSON and D. HENDERSON, "ALARA: Analytic and Laplacian Adaptive Radioactivity Analysis code," University of Wisconsin, UWFDM-1070, 1998.

[5] K. Wilson, T. England and K. Van Riper, "Status of CINDER'90 Codes and Data”, Los Alamos National Laboratory, LA-UR-99-361, 1999.

[6] International Commission on Radiological Protection, "Conversion Coefficients for use in Radiological Protection against External Radiation,” ICRP Publication 74, Ann. ICRP26, Pergamon Press, 1996. 